\title{
The Status of Geography in the Minnesota High Schools
}

\section{E. Huff}

To cite this article: C. E. Huff (1912) The Status of Geography in the Minnesota High Schools, Journal of Geography, 10:9, 298-304, DOI: 10.1080/00221341208985714

To link to this article: http://dx.doi.org/10.1080/00221341208985714

Published online: 20 May 2008.

Submit your article to this journal $\llbracket$

Џ Article views: 4

Q View related articles ¿ 


\section{THE STATUS OF GEOGRAPHY IN THE MINNESOTA HIGH SCHOOLS}

By C. E. HUFF,

West Side High School, Minneapolis

$T$ HE following questionaire was recently sent to the Superintendents tive to the status of high school geography. Seventy-six replies were received. These answers may be taken as representative of the conditions in the entire state. All the larger cities outside the Twin Cities replied, as did also a large number of smaller cities and towns in agricultural communities.

\section{SUPERINTENDENTS' QUESTIONAIRE}

1. What courses in geography are now offered in your high school?

Physical geography, number of months?

Political geography, number of months?

Commercial geography, number of months?

Other courses?

2. During what year in the course is each subject taught?

3. Is physical geography offered as a beginning science, or after other sciences have been studied?

4. To the average pupil, what is the relative importance of physical geography, as compared with other high school sciences?

5. What should be the purpose of the course in high school geography?

6. Of what practical value is geography in the high school?

7. All things considered, is the subject of sufficient importance to entitle it to a place in the agricultural and other industrial courses?

8. Considering the physical features and local industries of Minnesota, what phases of geography should receive special emphasis in the high school?

9. Are teachers given the same relative opportunity as to equipment and time for field and laboratory exercises as in other sciences?

10. In the past, have you found teachers as well prepared to carry on such exercises as teachers of other sciences are to do successful laboratory work?

11. From the pupil's standpoint, are you getting as satisfactory results from physical geography as from the same amount of time given to other sciences?

12. In what ways do you consider our present-day teaching of geography in high school weak?

13. What, in your opinion, is the principal weakness of the presentday physical and commercial geography texts? 
14. Has your teacher of geography in the high school had the same amount of special training in geography as he has in the other subjects he teaches?

15. Has he had the same amount of training in geography that other science teachers have had in the sciences they teach?

16. If you consider the training of the present-day geography teachers inadequate, please suggest what you think might be done to bring about better training in the near future.

17. If you attribute present weaknesses to other causes, please suggest how you think the weaknesses might be eradicated.

\section{SUMMARY OF ANSWERS RECEIVED}

Of the 61 answering the first question:

57 schools offer physiography $1 / 2$ year.

4 schools offer a full year's work.

9 schools offer political geography $1 / 2$ year.

3 schools offer commercial geography 1 year.

47 schools offer commercial geography $1 / 2$ year.

7 schools offer only commercial geography.

Of the 61 answering qu'estions 2 and 3 :

43 offer the work as a beginning science during the first or second high school year.

18 offer the work during the third or fourth year after other sciences have been taken by the student.

Of the 58 answers to question 4 :

33 state that pupils taking physical geography consider it of very small importance as compared with other sciences.

10 state that pupils consider it at least as important as other subjects.

15 misinterpreted the question. In these 15 the superintendent states that he considers it on a par with other sciences.

The following quotations from various letters indicate the general attitude of pupils toward the subject as now taught:

"a snap," "a filler," "inferior," "of little interest," "an odd end."

The answers to question 5 which had to do with the purpose of courses in high school geography, cannot be summarized numericallyOpinions were variously stated. Yet there is a uniformity of idea which may be expressed by quoting and connecting various answers: "The student's eyes should be opened to the world about him; he should learn in his geography study constantly to observe and reason." By the aid of the teacher and the text the student should learn to "discover for himself the influence of physical environment upon life and industries." $\mathrm{He}$ should reason out problems in accordance with natural laws and principles much as he would solve problems in physics and chemistry. "The aim should be to make the student realize that while many other than geographic in- 
fluences affect life, yet the geographic forces and agencies have fashioned and are now fashioning his place of habitation and occupation, that practically all industries are conditioned by and based upon geographic facts, that the whole past of the human race has been a tough struggle with geographic facts," and that, "geography is the background of the study of literature, history and economics" as well as of all the other sciences and of the industries.

Of the 66 answering question 7 :

56 answer that geography, especially physical geography, should be a part of all industrial courses.

10 say there is no time for it and that it should not form a part of such courses.

2 say that physical geography should be omitted and only commercial offered.

Such emphatic statements as the following are suggestive: "absolutely necessary in an industrial course," "yes, emphatically," "yes, if made a study of real things and not a text study only."

It is not easy to classify answers to question 8 , which called for an opinion as to what should be emphasized in the high school geography.

22 state that the study of weathering, erosion and soils is of first importance.

$\gamma$ mention waterways and drainage.

5 mention a study of local features and their relation to industries and life.

4 mention an elementary study of typical minerals.

3 say that soil areas, clay, sand and gravel deposits should receive more attention.

5 speak of weather and climate as very important.

10 call for a more careful relating of physical environment to life and industries.

Of the 65 answers to question 9 :

13 say that teachers are given the same opportunity as to time and equipment for field and laboratory work as in other sciences.

52 say they are not given the same equipment and time.

A few typical answers may be enlightening:

"Equipment not so good because teachers have not asked for it."

"No, sorry to say, they do not want it."

"No, but teachers do not know what constitutes equipment."

"Have known only two strong teachers of geography in ten years."

"No, teachers would be at sea, not knowing how to use apparatus."

Of the 63 answers to question 10 :

4 say they have been able to secure teachers as well prepared to do field and laboratory work as teachers of other sciences are to do successful laboratory work in other sciences. 
59 state that they have not been able to secure geography teachers thus equipped.

Of the 58 answers to question 11 :

32 say they are getting as satisfactory results from physical geography as from the same amount of time given to other sciences.

26 say they are not getting as good results.

Several modify these statements by saying that they do not get as satisfactory results, largely because students and teachers do not give as much time daily to physical geography as to other sciences.

Of the 63 answering question 12 :

21 state that our high school geography teaching is weak because teachers are not prepared to teach the subject.

29 attribute the weakness to poor methods, and to lack of proper field and laboratory exercises, which results in a slavish use of textbooks.

In reality these two sets of answers are identical in meaning, hence

60 state that the weakness is due to the fact that they can't get teachers who are prepared to teach the subject.

A number of the secondary reasons for weakness are interesting:

"Work too advanced."

"Too little time given to it."

"Too much attempted, too little done."

"Lack of equipment."

"Too abstract."

"Subject not vitalized and related to life, industrial and trade facilities."

"Too few men teachers of the subject."

"Too much text."

"Too much mere memory."

"Not enough work to warrant employing a special teacher."

Subject a "snap."

Subject a "filler."

Of the 31 answers to question 13 :

8 state that texts are weak in that they do not provide suitable laboratory and field exercises.

9 say that the texts include too many topics in ontline, and develop none of them thoroughly enough.

10 say texts give too little attention to the way man has responded to his environment.

8 suggest that texts are too vague and theoretical.

Of the 58 answering question 14 :

11 say their teacher of geography in the high school has had as much special training in geography as he has in other subjects he teaches. 
47 say he has not had as much training in geography as in other subjects he teaches.

To quote, several say:

"We can't get such teachers."

Of the 49 answers to question 15 :

8 state that their geography teachers have had as much special training in geography as other science teachers have had in their respective sciences.

41 say they have not had the same amount of training as other science teachers.

Of the 40 answers to question 16 :

26 say that teachers properly trained to teach high school geography can be secured only from the college or training schools offering a special course for this purpose.

Many such statements as the following are found among the answers:

"Colleges must rank this subject as at" least on a par with other sciences."

"The College of Education should be asked to offer suitable courses."

4 say, "Place the subject on par with other high school subjects."

Other answers cannot be classified. They follow:

"Raise the requirements of teachers."

"Correlate with other high school subjects."

"Activity by the Geographic Society of Minnesota should remedy the condition."

"Some one should issue an outline of the subject, with a field and laboratory manual specially adapted to the work in Minnesota high schools."

"Educate Boards of Education and superintendents to needs."

"Trgent call by superintendents would improve the conditions."

"A strenuous marking of papers in the state High School Board examinations would open the eyes of the teachers."

\section{CONCLUSIONS}

Physical Geography should be given as prominent a place in the High School curriculım as other sciences. Commercial geography should also occupy a place of prominence.

93 per cent. of the schools reporting offer one-half year's work in physical geography.

70 per cent. of the schools offer it as a beginning science. If this condition is to prevail and yet the subject hold as important a place in the course as opinions expressed indicate it should, much vague, unrelated material now presented will need to be eliminated or rearranged, and an orderly development of topics offered by inductive methods instead. If offered in the early years of the high school, the presentation must not 
assume a knowledge of other sciences. A more thorough and scientific presentation of physiography could be made if offered during the later years of the high school course. Many topics do not appeal to the younger, less trained mind as they would in later years. Principles mastered in other sciences are of material value in making a thorough presentation of certain topics. But not all the sciences can be offered in the later years, hence in many schools certain topics might better be eliminated and others developed and elaborated with more care. Many of the underlying principles should be worked out experimentally, even if in so doing one seemed to infringe upon fields of physics or chemistry.

As a basis of much of the later work, physiography is of sufficient importance to entitle it to a full year in the course. However, if this seems an unreasonable amount of time to devote to it, the wise teacher must select the more important topics, and omit others. Those selected, he will develop much more thoroughly than is done in the average text-book.

With possibly a dozen exceptions, there are no geography teachers in Minnesota in the sense that there are physics and chemistry teachers. There are those who hear recitations in the subject, but they do not teach it. It is shown by the testimony of teachers and superintendents, by observation and by the results of the State examinations, that in physiography the work has been very superficially performed in the past, and it would seem that unless some means can be devised by which the subject can be presented by more up-to-date methods, and by more specially trained teachers, it might better be dropped from most of the high school courses. No subject is worth much as "a snap," "a filler," or "an odd end."

However, the subject can be trimmed and so recast as to be a very important part of the high school course. If the same care is used as in other subjects, teachers, who can combine this with other subjects and do as good work in other subjects, will soon be available.

85 per cent. of those replying state that physiography should be offered in every industrial course. In an agricultural community, however, the phases which would appeal to the student, and which would be most profitable for detailed study, would evidently be different from those selected for detailed study in either a mining or an industrial community. Here it would seem, there is apt to be a growing demand for physiography teachers who not only can teach well, but who are so thoroughly familiar with materials and methods that they can adapt the work to individual or community needs.

There is evidently need of improvement in equipment, but this will readily come to those who can give value received in results.

An urgent call for the preparation of teachers is indicated by the fact that 95 per cent. of those reporting state that they cannot get teachers. who are prepared to do satisfactory work in geography. Whether or not 
all schools would be ready to employ such a specially trained teacher at once does not matter. As the preparation must necessarily come somewhat gradually, the schools will, one by one, come to a realization of their need. This call seems the more urgent when it is noted that of the forty superintendents offering suggestions as to remedies, twenty-six suggest specifically that the college or university should be asked to provide courses which would insure as thorough preparation in this subject as in other sciences.

In fact the whole problem seems to be one relating to the teacher. Opinion indicates that physiography is not only a fit subject for the high school, but a necessary subject. Why it has been a failure as a high school subject up to the present time, is difficult to answer, unless it be that, except in rare instances, it has been entrusted to teachers who are in no way prepared to treat it as a science. One can scarcely understand for instance how a thoroughly trained teacher could. develop such a topic as the work of running water without familiarizing one's students with the great rivers of the earth; their names and locations; their characteristics, similarities and differences; their work; their valley plains and their relation to the life, industries and population centers of that part of the world in which they are located. And though these are not found in the text, the teacher of superior knowledge will see the subject from so broad a perspective that they will of necessity link themselves with principles presented in the text and discussed by the class. The same should also be true of every topic discussed. Moreover, it is evident that such a presentation will necessitate daily use of globes and physical maps during both the recitation and study periods.

Since there seems to be such uniformity of opinion as to the value of geography, it is difficult to understand why schools have not long ago insisted upon teachers of better preparation. Such insistance will soon show whether physiography is to take its place with other science or be dropped from high school courses.

\section{COLLEGE STUDENTS' KNOWLEDGE OF GEOGRAPHY}

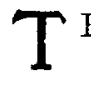

HE following ten questions were giveen a class of students at the

University of Wisconsin before they commenced a course in college geography. The examination is based upon no college work, but was designed to determine how much geography the students had retained from the grammar school course, and from reading the newspapers, taking history and economics courses, etc. The examination was taken by 128 students, 42 per cent. of them above the freshman class.

These were the questions:-

1. On an outline map with state boundaries write the names of the states in the United States. (5 minutes). 